\title{
Butyric Acid
}

National Cancer Institute

\section{Source}

National Cancer Institute. Butyric Acid. NCI Thesaurus. Code C68327.

A saturated short-chain fatty acid with a 4-carbon backbone. Butyric acid is commonly found in esterified form in animal fats and plant oils. 